\section{Treatment of locally advanced breast cancer}

$\mathrm{A}^{\mathrm{s}}$ $s$ the Steering Committee on Clinical Practice Guidelines for the Care and Treatment of Breast Cancer points out, ${ }^{1}$ locally advanced breast cancer comprises a heterogeneous group of breast tumours. Because of the complex needs of these patients, including the requirement for combined-modality treatment, we have established a specialized clinic for the treatment of women with locally advanced breast cancer at the Toronto-Sunnybrook Regional Cancer Centre, the first and largest of its kind to provide appropriate interdisciplinary care ${ }^{2}$ for this group of patients.

We would like to add a few points to the analysis presented by the Steering Committee. The recently published guideline $e^{1}$ discusses only the role of chemotherapy in the neoadjuvant setting. Currently, however, neoadjuvant hormonal therapy with third-generation aromatase inhibitors is gaining importance in this population, especially for an elderly, postmenopausal woman whose breast cancer is positive for estrogen receptor or progesterone receptor. The importance of neoadjuvant therapy with aromatase inhibitors and the superiority of these agents over tamoxifen in this setting has been demonstrated in 2 randomized trials.,4

The authors discuss the evolving role of aromatase inhibitors in the adjuvant setting, ${ }^{5}$ but other recent studies have shown the benefit of these drugs after tamoxifen. ${ }^{6,7}$ The rapidly accumulating evidence in favour of aromatase inhibitors necessitates frequent updating of guidelines with respect to adjuvant hormonal therapy.

Taxane therapy should now be considered the standard of care. The authors mention the results of 2 large trials ${ }^{8,9}$ that clearly showed a substantial improvement in the pathologic response among patients receiving taxanes in addition to anthracyclines. Recent presen- tation of longer follow-up to one of these studies ${ }^{10}$ provides more evidence of improvement in survival with the addition of taxane chemotherapy.

\section{Sunil Verma}

Mark Clemons

Barbara Fitzgerald

\section{Orit Freedman}

Toronto-Sunnybrook Regional Cancer

Centre

Toronto, Ont.

\section{References}

1. Shenkier T, Weir L, Levine M, Olivetto I, Whelan T, Reyno L; Steering Committee on Clinical Practice Guidelines for the Care and Treatment of Breast Cancer. Clinical practice guidelines for the care and treatment of breast cancer: 15 . Treatment for women with stage III or locally advanced breast cancer. CMA7 2004;170(6):983-94.

2. O'Rourke MW. Rebuilding a professional practice model. The return of role-based practice accountability. Nurs Admin Q 2003;27(2):95-105.

3. Ellis MJ, Coop A, Singh B, Mauriac L, Llombert-Cussac A, Janicke F, et al. Letrozole is more effective neoadjuvant endocrine therapy than tamoxifen for ErbB-1- and/or ErbB-2-positive, estrogen receptor-positive primary breast cancer: evidence from a phase III randomized trial. 7 Clin Oncol 2001;19(18):3808-16.

4. Smith I, Dowsett M; IMPACT Trialists. Comparison of anastrozole vs tamoxifen alone and in combination as neoadjuvant treatment of estrogen receptor-positive (ER+) operable breast cancer in postmenopausal women: the IMPACT trial [abstract]. Breast Cancer Res Treat 2003;82 (Suppl 1):S6.

5. Baum M, Buzdar AU, Cuzick J, Forbes J, Houghton JH, Klijn JG, et al; ATAC Trialists' Group. Anastrozole alone or in combination with tamoxifen versus tamoxifen alone for adjuvant treatment of postmenopausal women with early breast cancer: first results of the ATAC randomised trial. Lancet 2002;359:2131-9.

6. Goss PE, Ingle JN, Martino S, Robert NJ, Muss $\mathrm{HB}$, Piccart MJ, et al. A randomized trial of letrozole in postmenopausal women after five years of tamoxifen therapy for early-stage breast cancer. N Engl 7 Med 2003;349:1793-802.

7. Coombes RC, Hall E, Gibson LJ, Paridaens R, Jassem J, Delozier T, et al. A randomized trial of exemestane after two to three years of tamoxifen therapy in postmenopausal women with primary breast cancer. N Engl 7 Med 2004;350 (11):1081-92.

8. Smith IC, Heys SD, Hutcheon AW, Miller ID, Payne S, Gilbert FJ, et al. Neoadjuvant chemotherapy in breast cancer: significantly enhanced response with docetaxel. 7 Clin Oncol 2002;20:1456-66.

9. Bear HD, Anderson S, Brown A, Smith R, Mamounas EP, Fisher B, et al. The effect on tumor response of adding sequential preoperative docetaxel to preoperative doxorubicin and cyclophosphamide: preliminary results from $\mathrm{Na}-$ tional Surgical Adjuvant Breast and Bowel Project Protocol B-27. 7 Clin Oncol 2003;21:4165-74.

10. Hutcheon AW, Heys SD, Sarkar TK, Ogston $\mathrm{KN}$, Eremin O, Walker LG, et al. Docetaxel primary chemotherapy in breast cancer: a five year update of the Aberdeen trial [abstract 11] Breast Cancer Res Treat 2003;82(Suppl 1):S6.

Competing interests: None declared.

DOI:10.1503/cmaj.1040532

W e would like to raise another issue related to adjuvant chemotherapy for the treatment of women with locally advanced breast cancer. ${ }^{1}$ For adjuvant therapy of patients with nodepositive, operable breast cancer, crosstrial comparison over similar follow-up periods has indicated a greater risk of acute leukemia with more anthracyclines and alkylators. Specifically, among patients treated with 4 cycles of adriamycin and cyclophosphamide (AC) followed by 4 cycles of paclitaxel, the incidence of acute leukemia ranged from $0.25 \%$ over a 69 -month follow-up period ${ }^{2}$ to $0.18 \%$ over a 36-month follow-up period. ${ }^{3}$ For regimes of 6 cycles of anthracyclines and alkylating agents, the risk of acute leukemia was much greater: $1.42 \%$ over 59 months with cyclophosphamide, epirubicin and fluorouracil (CEF) ${ }^{4}$ and $1.17 \%$ over 48 months with epirubicin and cyclophosphamide. ${ }^{5}$ Even as therapy with AC followed by paclitaxel is being compared with a CEF regimen in the randomized phase III MA.21 trial (being conducted by the Clinical Trials Group of the National Cancer Institute of Canada), this side effect profile should not be ignored in discussions of adjuvant chemotherapy.

Given these data, the use of taxanes should be covered in clinical guideline development.

\section{Deepu Mirchandani \\ Kamal Haider \\ Haji Chalchal \\ Saskatoon Cancer Center \\ Allan Blair Cancer Center \\ Saskatoon, Sask.}

\section{References}

1. Shenkier T, Weir L, Levine M, Olivetto I, Whelan T, Reyno L; Steering Committee on Clinical Practice Guidelines for the Care and Treatment of Breast Cancer. Clinical practice guidelines for the care and treatment of breast cancer: 15 . Treatment for women with stage III 